Check for updates

Cite this: RSC Adv., 2018, 8, 36200

DOI: $10.1039 / c 8 r a 90080 a$

www.rsc.org/advances

\section{Correction: Synthesis and characterization of amorphous precipitated silica from alkaline dissolution of olivine}

\author{
Nadeem Raza, ${ }^{\text {ab }}$ Waseem Raza, ${ }^{c}$ Silvia Madeddu, ${ }^{a}$ Henry Agbe, ${ }^{a}$ R. V. Kumar ${ }^{a}$
} and Ki-Hyun Kim*d

Correction for 'Synthesis and characterization of amorphous precipitated silica from alkaline dissolution of olivine' by Nadeem Raza et al., RSC Adv., 2018, 8, 32651-32658.

The authors regret that there were some errors in the synopsis of ref. 4 (A. Lazaro, H. Brouwers, G. Quercia and J. Geus, Chem. Eng. $J ., 2012,211,112-121)$ in the original article. There was a misleading comment in the second last paragraph of section 1 (Introduction) of the article. Readers should disregard the following sentence:

"However, no attention was paid to deducing the rate-determining step in the acid dissolution of olivine."

This sentence is not appropriate as Dr Lazaro has already published an article in 2015, shown as ref. 1 below, which described the rate determining step in the acid dissolution of olivine. This reference should have been cited at this point in the introduction in the original article.

If the authors do not draw attention to the aforementioned sentence, it may mislead readers regarding the presence of previous efforts made in this subject. They thank Dr Lazaro, the lead author of ref. 4, for bringing this to their attention.

The Royal Society of Chemistry apologises for these errors and any consequent inconvenience to authors and readers.

\title{
References
}

1 A. Lazaro, L. Benac-Vegas, H. J. H. Brouwers, J. W. Geus and J. Bastida, Appl. Geochem., 2015, 52, 1-15, DOI: 10.1016/ j.apgeochem.2014.10.015. 